\title{
Structure of Person's Psychological Resources in Emergency Situations
}

\author{
Naira Hakobyan \\ Doctor of Sciences in Psychology \\ Professor, National Academy of Sciences of the Republic of Armenia \\ nhakobyan@mail.ru \\ Anna Khachatryan \\ Ph.D. in Psychology \\ National Academy of Sciences of the Republic of Armenia \\ anna.khachatryan@cba.am
}

\begin{abstract}
A person lives and works in society. Out of the social environment, it is impossible to imagine any aspect of a person's life. In many cases, the characteristics of the social environment depend on the means and interaction of the person's psychological resources. A person uses different resources at different stages of life. A good share of these resources in the majority of cases are not appreciated and perceived as ordinary means of life. In some cases these resources cannot be reached because of conflict with negative psychological phenomena, whether it is a traumatic or negative past experience or an irrational thinking. This is why the appropriate trainings for reducing the impact of these negative phenomena and providing stressresistance are of much importance. On the other hand, the knowledge and skills gained during the trainings can be useful and applicable in process of overcoming possible conflicts and coping with potential emergencies. Due to psychological resources, helping to adapt to stress, it is easier to get out of the stressful situation. KEYWORDS: Psychological resources, social environment, cognitive coping resources, emotional coping resources, behavioral coping resources, sociopsychological stability
\end{abstract}


The socio-psychological factor in structure of mental health of a person is presented by three-dimensional model of adaptive psychological resources, existence of which allows the person to define the adaptation term as a psycho-social adaptation mechanism.

In this review the following types of psychological resources are identified:

- cognitive coping resources, applying positive thinking to the cause of stress and ways to overcome (constructive and destructive cognitive effects of adaptation);

+ emotional coping resources;

+ behavioral coping resources.

Cognitive Coping Resources present the capabilities and knowledge of a person in emergency situations, and then, in the process of overcoming these situations and in self-transformation into regular life. Secondly, in the case of destructive cognitive impairment, there will be weakness of attention, expression of rejection of society, and will indicate the inability of a person to move to a regular course of life.

Emotional Coping Resources present awareness and perception of person's own feelings and emotions. Here, too, we can highlight the emotional structural effects of adaptation, as well as the sophisticated emotions, controlling the dynamics of emotion and guiding both the positive emotions, and such types of destructive effects as fear, sadness, anxiety and impotence.

Behavioral Coping Resources provide the expression of the first two types in a person's vital activity. Based on the logic of the structured classification of the above mentioned psychological resources, we can also take the behavioral factor into the same pattern and examine as cognitive behavioral and emotional behavioral resources. The first of these would indicate behavioral features that are largely driven by cognitive resources. The conceptual framework of emotional behavior, in turn, will constitute a manifestation of behavior resulting from the person's emotions. Each type of behavior, similarly, will be subject to general infrastructure classification as constructive and destructive components of cognitive or emotional behavior, expressed in constructive and destructive forms of social behavior.

Many researchers say that the positive social environment (family, friends) can contribute to the preservation and strengthening of a person's stress-resistance. In this regard, the social environment is seen as a socio-psychological resource to overcome stress. In his turn, B. G. Anan'ev writes about the impact and significance of moral support and compassion on other people's socio-psychological stability (Ananev 1998). 
F. Novice also revealed the interconnection between stress and social assistance and support. Many psychologists point out that in the case of social immediate support, a person is able to overcome stress faster (Ensel, Lin 1991; Nadler 1991).

$\mathrm{N}$. Weinstein believes that after the emotional stress, a person's mental health is endangered when there is a feeling of powerlessness when a person feels alone (Weinstein, Klotz, Sandman 1988). That is why social support can be viewed as a mechanism to minimize stressful adverse effects.

Social support forms are separated according to the following ones:

+ institutional (state or administrative),

+ workplaces (corporate),

- trade unions, NGOs, groups of interests or the "other corporate"

+ informal (family, friends and other).

In general, the material, emotional and informational forms of social support are distinguished. Social support helps to prevent distress development. Many studies have discovered that people with social support are less depressed. It is also a fact that women tend to seek support from other women, but not less important is the acquisition of social support for men.

Psychological literature has quite a variety of psychological resources definitions (Janof-Bulman, Lang-Gunn 1988; Philips 1968; Kobasa, Puccetti 1983). Thus, N.E. Vodopianova (Vodopianova 2009) in terms of psychological resources includes skills and knowledge, experience and capabilities, constructive behavior models, actual abilities that give the person the opportunity to be more adaptive and stress-resistant, successful and satisfied quality of life. The majority of the authors distinguish the terms of internal (personal) and external resources. The latter classification can be used as a methodological basis for the stress trainings organization and development. Some authors view the issue of person's behavior in the context of adaptation theory. Adaptation is understood as both the process and the result of a person's behavior vis-à-vis internal changes and new conditions. The adaptive abilities of body represent the criterion for maintaining the natural functioning in inadequate environment. At the individual level, it is important to maintain vital functions of the organism or to switch to another inadequate functions. An important factor in the adaptation process to the environment is mental adaptation. It is dynamic process of maximizing compliance with the individual and the surrounding environment, which enables a person to satisfy his needs and to meet the environment's requirements. Psychological 
adaptation is divided into allografts and intravenous units, the first of which means the adaptation at the external, behavioral level, and the second, the psychological self-protection mechanisms. In stressful situations, such defensive mechanisms often complicate the self-regulation process of person's personality, distorting perceptions about the individual (Berezin 1988).

From the perspective of adaptation, emergency situations can be short-term and longterm. In the first case, the primary protection mechanisms for personal protection are activated. In case of long-term emergencies, there is a need for adaptive reconstruction of the whole human functional system. In other words, long-term stress is associated with the cost of adaptive storage, may be hidden, only in the alteration of the adaptation indicators. In this case, adaptation can be successful if a person adapts to the conditions of a long-term emergency, mobilizes his deep, hidden resources (Kalaikov 1984). As examples of such long-term stress may be suggested the high risk areas of natural disasters, prolonged war situations, political and economic crises, and so on. In such stressful situations, the author suggests a special type of stressor that requires specific adaptation mechanisms. On the other hand, long-term stresses form the perception of these situations as an "ordinary" phenomenon; there are adaptive levels that weaken the stress perception and contribute to the normal functioning of a person in such conditions.

Hiley-Young, in his turn, sets out stress management or adaptation factors such as the degree of readiness for natural disasters, social support immediately after the disaster, the surrounding environment, disaster periodicity, and the urgent help of professionals, psychologists, psychiatrists, rescuers and social workers (Hiley-Young and Gerrity 1994). Let us also note that certain studies (R. Lazarus's spelling behavior (Lazarus and Folkman 1984), J. Lotman's culture theory (Lotman 2001), S. Nartova-Bochaver's coping behavior (Nartova-Bochaver 1997)) point out the dependence of person's adequate stress in stressful situations on the individual's adaptive capabilities, on the peculiarities and appreciation of the situation. The choice of behavior in this or that orientation can be done both at unconscious and conscious levels, and the effectiveness of the strategy chosen depends largely on the extent to which the particular situation is under the control of a person. This conclusion was also made by S. Madde, who pointed out cases when a person, taking responsibility for himself, has managed to control the situation in some way, thus becoming more resistant and resilient (Madde 2002). In modern Russian psychology, the concept of personality appreciation has also been revealed which is responsible for adaptation of a person, such as the concept of personalized adaptation potential of A.Maklakov (Maklakov 2001, 16-24) and D. Leontev (Leontev 2002). 
Personality adaptation capabilities are assessed at the level of development of a person's psychological characteristics, which is more remarkable for regulation of a person's mental activity including the higher level of these characteristics, the greater likelihood of person adaptation and the significant external adaptive factors. The psychological peculiarities of a person are his/her personal adaptation potential that includes nervouspsychological stability, self-esteem, social support, personality conflict, and social interoperability. A. Maklakov describes all characteristics of assessment and prediction of the significant adaptation, as well as in the restoring the person's mental balance.

D. A. Leontev uses the term "personal potential", which is an integral characteristic of personal maturity. The basic forms of expression of personal maturity are the concept of self-regeneration and self-esteem. The potential of the person reflects the efforts of the person to overcome the emergency situation. Consequently, overcoming can be person's protective function. If the psychological overcoming, based on person's endurance, leads to the development of self-centeredness, an intermediate link will appear in a kind of transformation that is specific to a person in the state of emergency or socialization. So the overcoming is a skill that appears in course of the person's socialization. In the case of such personal qualities, it is also possible to define the person's ability to endure life, which is being formed during difficult life situations, particularly, in overcoming emergencies.

Different ways of internal adaptation or defensive behavior can be viewed as a type of overrun, based on other resources and skills. Personal resources in this case have a secondary role, they can even be excluded from the overcoming process. In this case, psychological overcoming is not defined by purely personal qualities, they are presented simultaneously. The predominant use of protection mechanisms can lead to personalized integration, but in emergencies, when it is necessary to directly influence the individual's integration and adaptation skills, such mechanisms are extremely useful and contribute to a person to "assemble by force" and to invest in a mature transformation resources. The person's resources are the main adaptation resources. Even their direct availability ensures the activation of the person's adaptive function, which is expressed in the sense of identity identification, self-esteem and self-confidence. As an adaptation resource, you can consider everything that a person uses to meet the needs of the environment and overcomes difficult life situations. In modern psychology, two types of resources are distinguished: individually or internally and externally or internationally. Sometimes they are called psychological and social resources. Psychological resources include personal skills and abilities, and environmental resources reflect institutional, ethical, and emotional access to the social environment. The success of stress management and adaptation depends largely 
on the nature of available and accessible resources. Thus, moral stability promotes endurance in emergency situations, and faith in its effectiveness, in demonstrating persistence in solving problems. The availability of material resources allows access to information, legal, medical, and other forms of professional assistance, as access to social resources is different, and it can be assumed that more vivid picture of the powerlessness and vulnerability of people with low economic status in emergencies is the economically sound and sustainable living-class layers. It is also clear that people who lack resources are often choosing an exclusive strategy compared to those who have different resources. It should be noted that this separation is unequivocal and many cases are known when a person experiences a lack of resources in the presence of a variety of resources. In other words, the resources remain unused. In this case, it is extremely important to identify obstacles that lead to inefficient use of resources. Such obstacles include cultural peculiarities, traditions, public opinion, personal qualities. Experimental studies conducted by a number of authors have shown that the stereotype of seeking help in an emergency situation is related to respect for one's own self, respect for the sense of independence, factors that conceal his/her own weakness and powerlessness (Greenfield and Bruner 1969).

In the summary of different approach analysis, it is possible to identify some of the external, interpersonal relationships and some purely psychological characteristics that increase the person's sustainability on stress and psychological factors. Such psychological characteristics can be defined as psychological resources for adaptation to personal emergency situations. Different types of adaptation are separated from those related to the person's perceptions about the world and his personality, about the importance of his existence. Additionally, as a person's resource, the application of the knowledge and conduct of the person in emergency situations is observed. The oftenperceived idea of the research relates to the phenomenon of the control of the person in emergency situations (Norris and Kaniasty 1996). The person's status internally is expressed in the ability and willingness of the person to overcome the difficulties of life. In contrast to this pole, a certain position of a person's powerlessness appears, characterizing the inability of a person to make decisions and take responsibility. This phenomenon is called "socialized powerlessness" and characterizes person's adaptation mechanism based on the utilization and spending of external resources and, at the same time, on the maximum preservation and conservation of psychological resources. Like the psychological resources, the "freezing" mechanism, being parasitic in its nature, can only provide for person's protection over a certain period of time. This phenomenon can be described as "a social adaptation twist". The person gradually begins to learn about his position of being powerless and the necessity of social support, which, in 
the case of its periodicity or interruption, has psychological effects. In contrast, those with an international outlook believe that the situation with them is largely driven by their activities, and, accordingly, their sense of responsibility towards their personality and surroundings increases.

In this regard, let us present the position of V. Frankl that in extreme situations the person is more resistant, if he realizes his/her meaning, that is, if a person realizes that he/she is living all the difficulties of life (Frankl 1990).

J. Crumbaugh, presenting his observations on the psychological consequences of natural disasters, also points to the fact that those who see the meaning and purpose of their lives have been overcome with more difficult living conditions. Thus, the realization of the meaning and purpose of life, the meaning of its own "I" is a powerful factor aimed at raising the person's stability and outward adverse conditions. Foreign research also includes works devoted to the role of values in psycho-logical situations (Crumbaugh 1968).

The psychological maturity of a person, expressed through the concept of "psychological age," affects the ability of a person to effectively counteract the most challenging situations. Mature attitudes toward their own life, and on the contrary, significant deviations from psycho-logical and chronological age testify to the discontinuity of mechanisms to counteract mental traumatism. Let us note another fact: the future planning in terms of raising the person's sustainability to the psychological situation. The lack of such planning is a test of stress in a traumatic situation. Thus, one of the key features of the coping strategy is the inclusion of the given situation in its own vital experience and a rational assessment of that experience, which contributes to the further valuation of the future.

Turning to the factors of person adaptation, R. Lazarus and S. Folkman (1984) point out the necessity of recognizing the regularity of the ongoing processes. Knowledge of the rules of behavior in emergency situations is a cognitive resource of coping, based on personality knowledge about the patterns of occurrence and the mechanisms of occurrence and overcoming of these phenomena. The importance of understanding the processes taking place in such situations is also mentioned by M. Mamardashvili (Mamardashvili 2000). Understanding allows a person to "fill" the matter with personal meanings. H. Kelly assumes that the impact of the subjective planning of processes on all sides of physiological processes, but also on the individual's life cycle (Kelley 1967). Likewise, L. Antziferova (1994, 3-18) believes that the person's ability to plan situations and the knowledge of the underlying patterns of these processes are the most important factor in reducing the traumatic effects of sudden emergencies. 
Mental regulation is impossible without the planning of present and possible future coincidences, so it can be seen as the principle of optimal management based on mental adaptation, physiological systems, based on the expected image of future events. Consequently, the ability a person to effectively adapt to an emergency directly depends on his/her ability to plan the future.

Along with the above resources, the person also possesses behavioral resources. These are, first of all, behavioral skills during and after the emergency. It is important to note that the above-mentioned psychological resources are periodically supplemented and formulated throughout life. Psychological resources for adaptation and overcoming are presented as the main characteristics of a person who not only describe, but also mediate the impact of adverse conditions. A person is adapted to a wide range of stress situations. J. Picou points out that the resistance to stress is perceived by the source of stress, the state of emergency (Picou, Marshall and D. Gill 2004).

According to the sources, three types of emergency situations can be identified:

- The source of stress is independent of the individual and is fundamentally unpredictable (natural disasters).

- The source of stress is the mentality of the individual.

- The state of emergency is created by other people (war, terrorist acts).

Psychologically, the situations in which other people are guilty of and the overcoming of which are not primarily dependent on the person who is in that situation, psychologically "the lightest" in the emergency situations is the situation that does not depend on anyone's will. Natural disaster, but in this case the overcoming of this situation largely depends on the person's activism and the ability to use psychological resources if it is not accompanied by a large number of victims. Here's another peculiarity of natural disasters. They occupy large areas and often disrupt the infrastructure of the social structure, which also leads to the increase in the number of victims and destructions. However, some authors, nevertheless, point out that large-scale techno-genic emergencies have a more profound social and psychological impact than natural disasters.

\section{Methods}

A three-dimensional (cognitive, emotional, behavioral) model of adaptive psychological resources is a socio-psychological factor in mental health. The psychological resources of a person in emergency situation are of compensatory nature, which is expressed 
by a positive social adaptation strategy. This definition of psychological resources nature was discovered due to modification of "cultural-evaluative differential" method by G. Soldatova (Soldatova 1998, the questionnaire idem). Psychological resources were evaluated in accordance with cognitive, emotional and behavioral indicators shown below. During experimental investigation of this hypothesis several groups of respondents living in the capital of the Republic of Armenia (102 men and 110 women) were involved in the process of describing the psychological resources' structure and their evaluation. The results of the investigation are the following.

Cognitive resources evaluation indicators are disproportionate and can only be attributed to the dominant preparation training feature as a major security factor, and are not connected with the external information feature. Although these indicators are characterized as one structural integrity they are perceived individually and suggest that the security of the external social environment needs additional safeguarding. In this regard, a broad field opens up for further study of the field to identify the peculiarities of person's value system, the national mentality. At this stage of investigation, we can assume that this disproportionate craving of resources is conditioned by the need for personal security in an emergency situation and is compensated by a more vigorous expression of emotional and behavioral resources, such as optimism and usefulness (Figure 1).

\section{Figure 1. Cognitive Resources Evaluation Indicators}

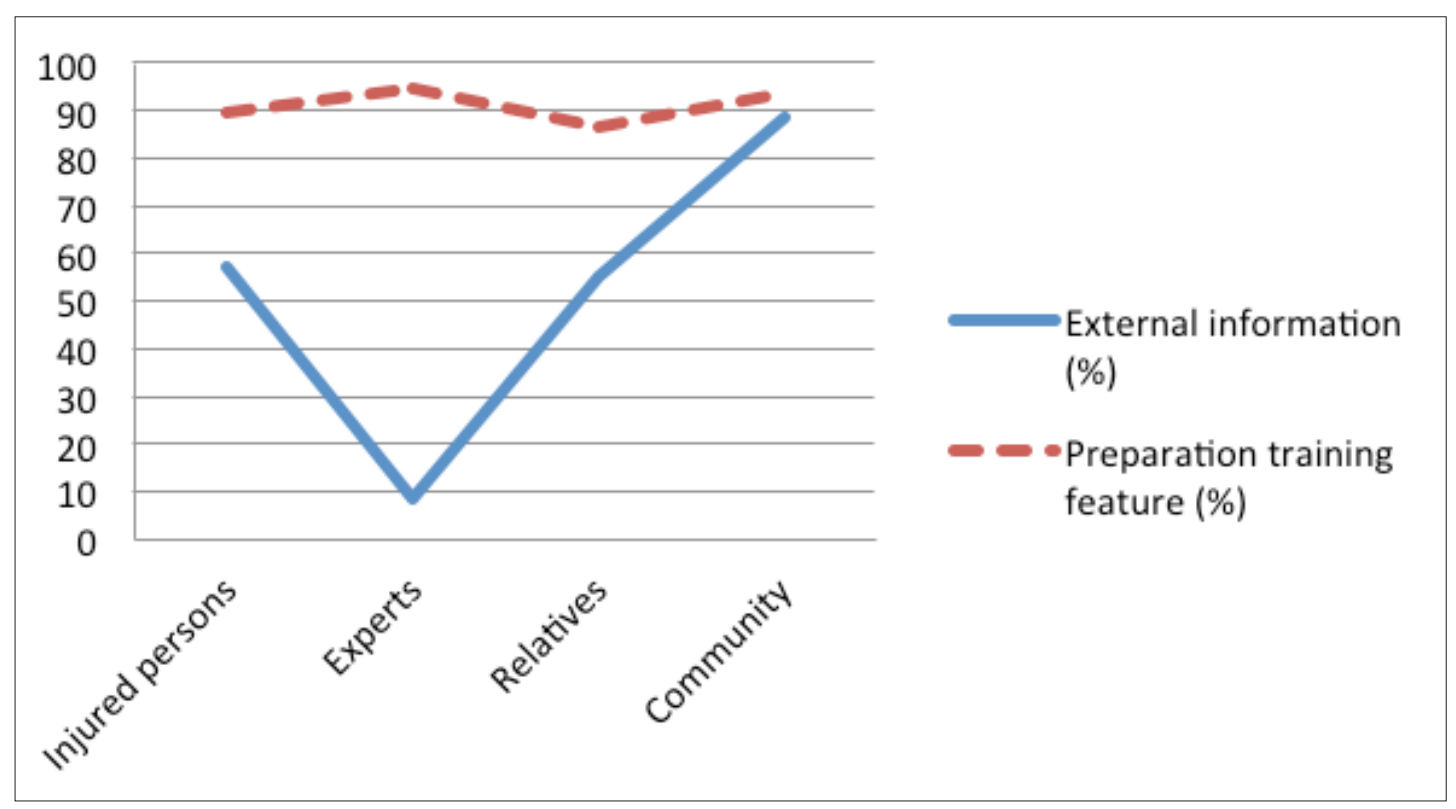


Functional cooperation and positive correlation between adaptive optimism and usefulness as emotional resources have been registered in an emergency. And vice versa, the growth of adaptive pessimism is accompanied by an increase in the sense of powerlessness in all sample groups (Figure 2).

Figure 2, Emotional Resources Evaluation Indicators

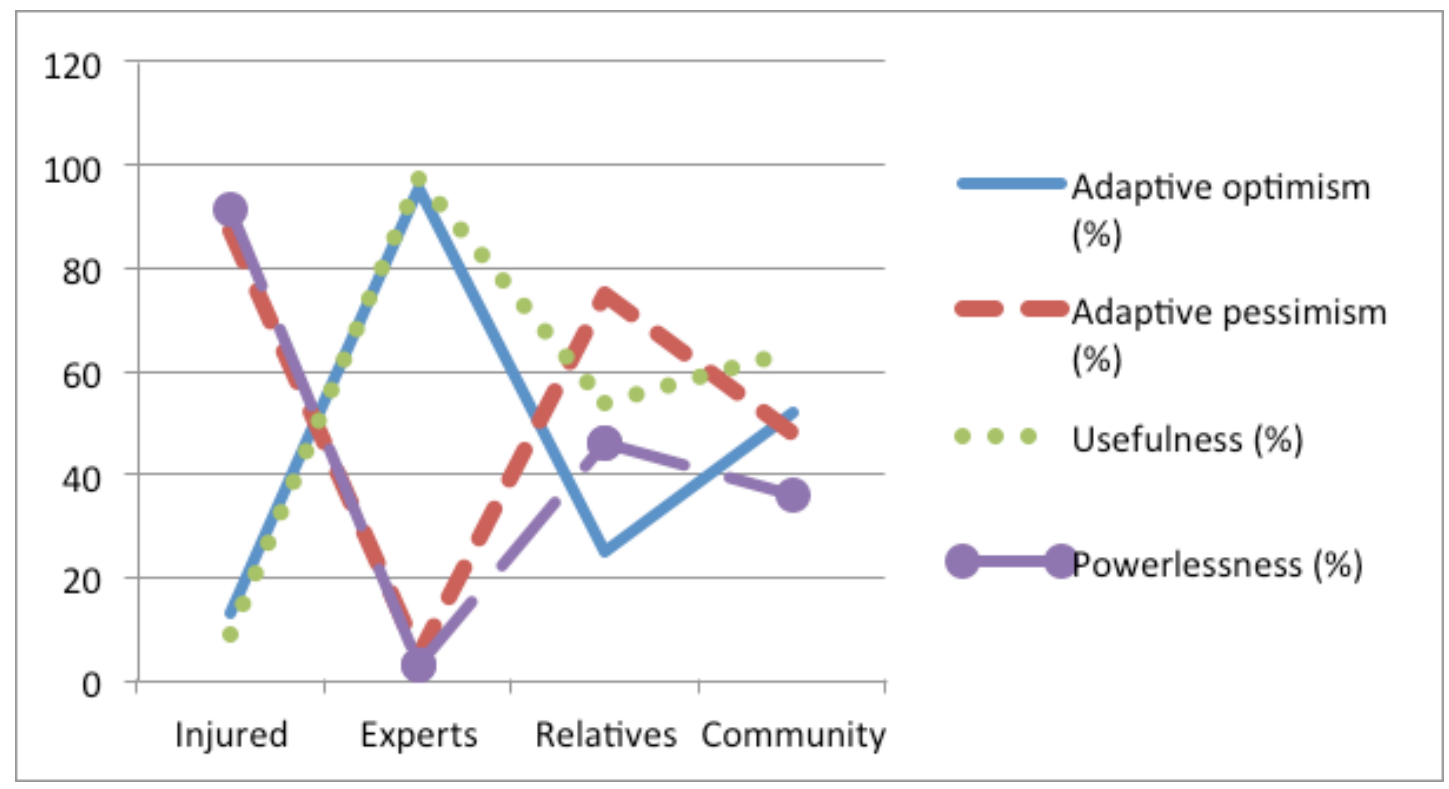

The index of behavioral resource of self-support for injured persons is accompanied by caution in an emergency situation and is consistent with the position of cognitive resources, that is based primarily on their own experience in an emergency and has a weak social support. The growth of collaboration and, respectively, resoluteness, was observed in the qualification groups of experts (psychologists, doctors), relatives (a family, friends of injured person) and community (society), which testifies to the group-collaborative nature and adaptation of social support about the interconnection of constructive mechanisms and institutions of socialization (Figure 3). 
Figure 3. Behavioral Resources Evaluation Indicators

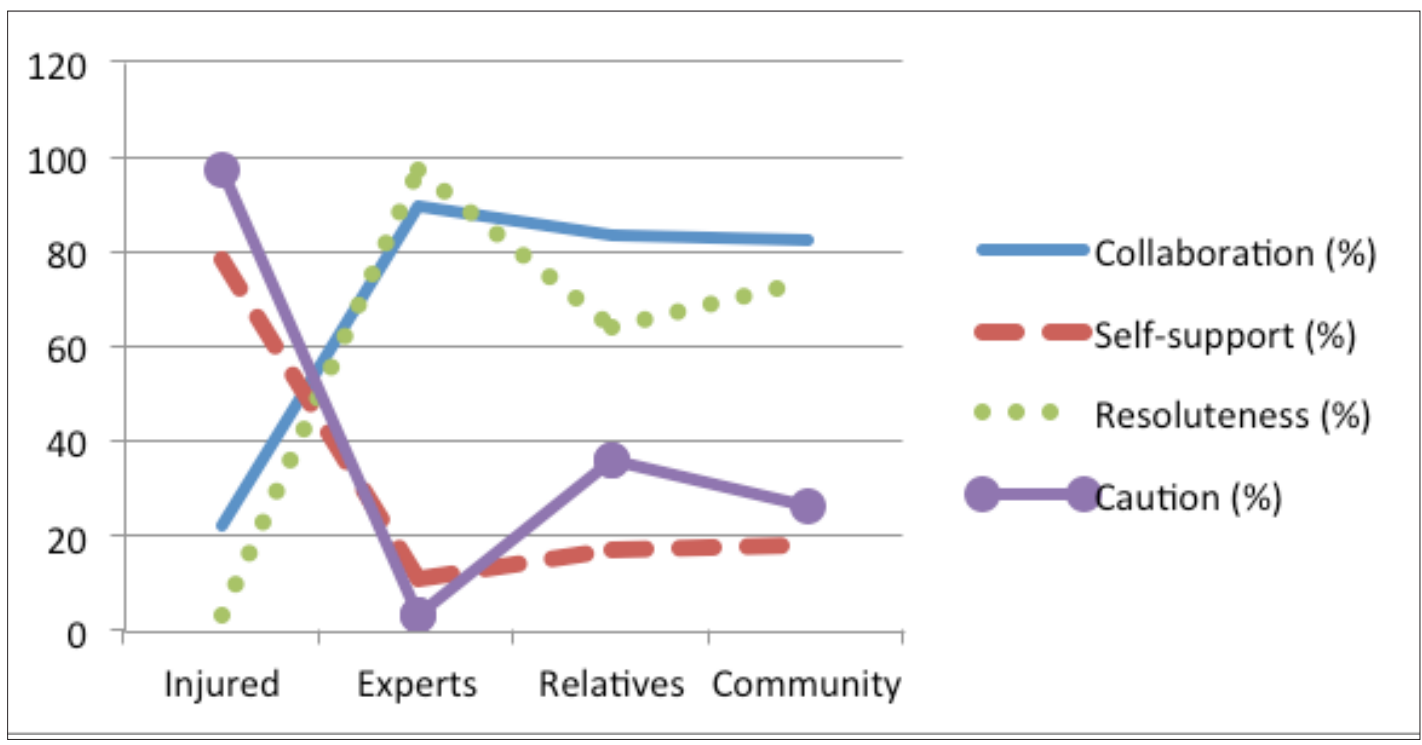

Structural interconnection of emotional and behavioral features is compensated by some distorted images and disproportionate manifestations of cognitive attributes. This conclusion can serve as a visual-methodological basis for psychotherapeutic and psychological work aimed at the person's social constructive adaptation process. Additionally, the importance and significance of the emotional environment is determined for the development of constructive mechanisms for the adaptation of the person to the emergency situation.

The responses of community representatives acting as the "observers" have been remarkably prominent with moral high standards. Indicators of adulteration have been registered in two stages depending on the participation of psychological trainings after an emergency. The first stage of the registered indicators reflected the degree of social-role units' adaptability before the trainings and psychological conversations, and the second stage recorded the change of adaptability of the same socio-role units after participating in trainings. As it is seen from graphics of adaptability, almost all indicators have a tendency of growth, expressed in the results of the second round of psychological trainings and conversations. An exception is the graphic representing moral norms, which shows the almost unchanged results of that indicator. This is how publicly accepted social, national and cultural stereotypes are consolidated in the person's socialization and represent the key role of a person's identity. 
So, Constructive Adaptation Process is possible in the case of complex operation with the person's psychological resources when the consciousness or understanding of the emergency situation is accompanied by an emotional well-being, which is gradually becoming dominant in the organization of personal behaviors. This interaction is of mutual nature and ensures the transformation of "cognitive-emotional" bipolar changing into constructive adaptation, expressed in the appropriate behavior.

Almost all respondents in socio-role groups emphasized the importance of access to external information. The respondents find the need for external information in the implementation of adaptive mechanisms. This trend of responses to the next cogitation resource, the overwhelming majority of respondents prefer to prepare in advance of emergency situations, such as prior knowledge of situations, familiarization with the rules of behavior in emergency situations, and knowledge of ways to get help. Similar indicators have been recorded in the relatives' group. Taking into account the relevance of their own experience, their estimates almost coincide with answers of the victims. The responses of the group's members are somewhat different. The majority of respondents also point out their own experience based on the adaptation effectiveness and not the availability of external information. This indicator is interpreted as being "witnesses" and unaware of the danger to their own identity. That is why the assessment of this group of attitudes is consistent with the following "community" responses.

At this stage of the analysis we can mark the following observations: In almost all the groups distorted perception of psychological cognitive resources and their transfer to the emotional and behavioral field are recorded. Simultaneously, the certainty and demand for answers to the social adaptation environment are noticeable. Adaptation group-to-peer component is the most important in the immediate emergency and the organizational and institutional component is highlighted in the post-stage and has a long-term effect. These considerations can serve as a basis for the study of a person's socialization process, as it expresses the key expectations of a person after the emergency, which are mainly related to the post-traumatic organization and reaction to the social institutions.

The following are the results of the socio-psychological transformation of adaptation, when in the post-stage phase almost all the electoral groups have a tendency not to adapt their adaptation process to the external environment, but rather to adapt the social environment to the new socio-role status acquired by a person. This mechanism of a "socialized powerlessness" is based on the "freezing" of psychological resources when a person gradually begins to adapt himself to the new position and expects the long-term social support of his new injured status. 


\section{Conclusion}

Summarizing the investigation of the relationship between psychological resources and social adaptation of the person, one can draw the following conclusions.

Adaptation to emergency situations is included in a person's socialization system.

- Psychological resources of an individual are important in terms of adaptation to newly emerging social structures due to emergency situations (types of cognitive, emotional and behavioral resources of a person's psychological resources).

- In the case of constructive expression of cognitive resources the person's abilities and knowledge are taken into account in emergency situations overcoming it and moving to the regular life.

- In the case of destructive effects of cognitive resources, the mentality of thinking is reflected and a person is unable to move to a regular course of life.

- Constructive effects of emotional resources are expressed in the possession of socio-metric feelings, controlling the dynamics of emotion and guiding the positive emotions.

- The destructive manifestations of the adaptation emotional resources are the emotions expressed in the form of fear, sadness, anxiety and depression.

- Adaptation behavioral resources provide the expression of the above-mentioned cognitive and emotional strains in person's life. Based on the logic of the psychological resources classification, one can also engage in the same pattern of behavior as a cognitive behavioral and emotional behavioral resources. The first of these would indicate the forms of behavior that are largely driven by cognitive resources. The conceptual framework of emotional behavior, in its turn, will constitute a manifestation of behavior resulting from the person's emotions. Each type of behavior, similarly, will be subject to general infrastructure classification as constructive and destructive components of cognitive or emotional behavior, expressed in person's socio-cultural behavior.

- The mechanism of adaptation of a "socialized powerlessness" has been discovered, which is based on the utilization principle using of external resources and, at the same time, maximum protection of psychological resources and "freezing". This mechanism has been described as a "social adaptation transformation" when a person gradually begins to adapt to his position of powerlessness and the mandatory presence of social support and expects the social acceptance of his new 
status taken in the emergency situation. In case of termination or interruption of social support, such position will have destructive psychological impact.

+ One of the main features of the emergency response strategy is the inclusion of the situation into a rational assessment of this experience, which contributes to the valuation of future life.

- Certain planning of the future is particularly important in terms of improving the person's sustainability. The lack of such planning is a test of stress in a traumatic situation.

\section{References}

Ananev, V. 1998. Introduction to Health Psychology. Saint Petersburg.

Antziferova, L. 1994. "Person in Difficult Living Conditions." In Journal of Psychology. N1.

Berezin, F. 1988. Mental and Psychophysiological Adaptation of Person. Leningrad: Nauka.

Crumbaugh, J. 1968. "Cross-Validation of Purpose in Life Test." In Journal of Individual Psychology 24(1): 74-81.

Ensel, W. and Lin, N. 1991. "The Life Stress and Psychological Distress." In Journal of Health and Social Behavior. Dec. 32(4):321-341.

Frankl, V. 1990. Man in Search of Meaning. Moscow: Progress.

Greenfield, P. and Bruner S. 1969."Culture and Cognitive Growth.” In Handbook of Socialization Theory and Research. Edited by Goslin. Chicago: RandMcNally.

Hiley-Young, B. and E. Gerrity. 1994."Critical Incident Stress Debriefing: Value and limitations in Disaster Response." In NCP Clinical Quarterly 4(2): 17-19.

Janof-Bulman, R. and L. Lang-Gunn. 1988. "Coping with Disease, Crime and Accidents: The Role of Self-Blame Attributions." In Social Cognition and Clinical Psychology: A Synthesis, edited by L. Abramson. Guilford, New York, London.

Kalaikov, I. 1984. Civilization and Adaptation. Moscow: Progress.

Kelley, H. 1967. "Attribution Theory in Social Psychology". In Nebraska Symposium on Motivation, edited by D. Levine, vol.15. Lincoln: University of Nebraska Press.

Kobasa, S. and Puccetti, M. 1983. "Personality and Social Resources in Stress Resistance." In Journal of Personality and Social Psychology 45: 839-850.

Lazarus, R. and S. Folkman. 1984. Stress, Appraisal, and Coping. NY: Springer.

Leontev, D. 2002. Contemporary Psychology of Motivation. Moscow: Smisl. 
Lotman, J. 2001."To the Construction of the Theory of Interaction of Cultures." In Semiosphere. Saint Petersburg: Iskusstvo.

Madde, S. 2002. Theories of Personality. Comparative Analysis. Saint Petersburg: Rech.

Maklakov, A. 2001. "Personal Adaptive Potential: Its Mobilization and Forecast in Extreme Conditions." In Journal of Psychology. Moscow, N1.

Mamardashvili, M. 2000. Aesthetics of Thinking. Moscow: Moscow School of Political Studies.

Nadler, A. 1991. "Help-Seeking Behavior: Psychological Costs and Instrumental Benefits." In M. Clark (Ed.), Review of Personality and Social Psychology 12: 290-312. New York: Sage.

Nartova-Bochaver, S. 1997. "Coping Behavior in the System of Concepts of Personality Psychology." In Journal of Psychology 18(5): 20-30.

Norris, F. and K. Kaniasty. 1996."Received and Perceived Social Support in Times of Stress: A Test of the Social Support deterioration Deterrence model." In Journal of Personality and Social Psychology 71: 498-511.

Philips, L. 1968. Human Adaptation and his Failures. NY \& London: Academic Press.

Picou, J., B. Marshall and D. Gill. 2004. "Disaster, Litigation, and the Corrosive Community." The University of North Carolina Press Social Forces (June), 82(4):1493-1522.

Soldatova, G. 1998. Psychology of Interethnic Tension. Moscow: Smisl.

Vodopianova, N. 2009. Psychodiagnostics of Stress. Saint Petersburg: Piter.

Weinstein, N., M. Klotz, and P. Sandman. 1988. "Optimistic Biases in Public Perceptions of the Risk from Radon." In Lessons from a Study in Radon Risk Communication. N.Y. 